\title{
故障と加速試験
}

\author{
岡本 秀孝 $*$
}

\section{Fault and Acceleration Test}

\section{Hidetaka OKAMOTO*}

*一般財団法人日本規格協会（１ 108-0073 東京都港区三田 3 丁目 13-12 三田 MT ビル）

* Japanese Standard Assoiation (Mita MT BLDG., 3-13-12 Mita, Minatoku, Tokyo 158-0073)

\section{1. はじめに}

本特集号の中で，本稿では，触れるべき項目は多いので あるが，「故障と加速試験」と題して加速試験の考え方，ワ イブル分布を中心として解説した。有益な情報を提供する ことを狙い，数式は最小限にとどめた。

\section{2. 故障と故障モード}

故障とは, JIS Z8115（ディペンダビリティ（信頼性）用 語）では, 「アイテムが要求機能達成能力を失うこと」と定 義されている。「アイテム」とは, 信頼性の対象となるシス テム, 機器, 部品, ソフトウエアなどを言う。「要求機能達 成能力」とは, 期待される機能のことである。故障には, 初期故障, 偶発故障, 突発性故障, 経時変化故障, 劣化故 障, 摩耗故障, 間欠故障などがある。

一方, 故障モードは, 同じくJIS Z8115（ディペンダビリ ティ（信頼性）用語）では,「故障状態の形式による分類, 例えば, 断線, 短絡, 折損, 摩耗, 特性の劣化など。」と定 義されている。故障モードは, 故障, 不良と区別される。 故障モードが引き金となって発生するのが故障であり, 故 障を引き起こした原因を故障モードと呼ぶ。不良は, 要求 性能を満たさない設計ミス, 不適切な製造過程で生じる欠 陥品を意味する。したがって，「故障」と「不良」には大き な違いがある。

\section{3. 加速試験 ${ }^{1)}$}

信頼性を評価するには，所定の年限の間材料や製品を放 置, あるいは実際の使用に供して評価するのが最も確実だ が，例えば 10 年の保証を確認するために 10 年間を費やす のは現実的ではない。そこで，製品を過酷な条件の下にお いて劣化を促進し, 長期間にわたる劣化が短期間に進むと みなして, 現実的な時間の試験で長期の劣化に代えるの が, 加速試験である。ここでは加速試験の考え方, 注意事 項について解説する。

\section{1 加速試験となる要件}

基準条件（例えば使用条件）より厳しい条件で部品や製 品の故障モードを促進することが，加速試験の目的である。

したがって，実使用条件と加速試験条件で故障モードが 違っては，加速試験の意味がなくなってしまう。どのよう な故障を想定するのか, どのような故障モードなのかを明 確にする必要があり，試験時間が短いというだけの試験 は, 加速試験ではなく過酷試験となる。簡単な例では, HAST 試験は加速試験としてよく使用されるが，HAST 試 験環境は $100^{\circ} \mathrm{C}$ 以上の高温な環境であるため, 実使用条件 で発生しない故障が発生していないことを確認することは 重要なことである。加速となる試験条件は, 高温, 高湿, 高電圧などがある。

\section{2 試験に必要な試料数}

信頼性試験には大きな二つの壁があると言われている。 その一つは時間でありもう一つは試験のサンプル数（コス ト）である。ここでは，信頼性試験に必要なサンプル数に ついて，数式を用いて説明する。

母集団の不良確率を $\mathrm{p}$ とすると，1個を試験して良品と 判定される確率は， $1-\mathrm{p}$ となる。したがって $\mathrm{n}$ 個の全ての サンプルが良品となる確率 P は,

$$
\mathrm{P}=(1-\mathrm{p})^{\mathrm{n}}
$$

となる。

式 (1)の両辺を $1 / \mathrm{n}$ 乗すると

$\mathrm{P}^{1 / \mathrm{n}}=1-\mathrm{p}$

となり, $\mathrm{p}$ について求めると

$$
\mathrm{p}=1-\mathrm{P}^{1 / \mathrm{n}}
$$

となる。式(3) の両辺の対数を取って, nについて求める と,

$$
\mathrm{n}=\log (\mathrm{P}) / \log (1-\mathrm{p})
$$

となる。

ここで, 信頼率は $1-\mathrm{P}$, 不良確率が $\mathrm{p}$ なので, 式 (4) か ら実際に計算すると，表 1 となる。

上記の表から，信頼率 $90 \%$ で不良率 $10 \%$ の結果を得る ためには，22 個のサンプルが必要なことがわかる。 
表 1. サンプル数（信頼率 $1-\mathrm{P}$, 不良率 $\mathrm{p})$

\begin{tabular}{c|c|c}
\hline $1-\mathrm{P}$ & $\mathrm{p}$ & $10 \%$ \\
\hline $90 \%$ & 22 個 & 230 個 \\
\hline $60 \%$ & 9 個 & 92 個 \\
\hline
\end{tabular}

\section{3 ワイブル分布 ${ }^{2)}$ とワイブルプロット ${ }^{3)}$}

ワイブル分布は, 物体の体積と強度との関係を定量的に 記述するための確率分布として 1939 年に提案された。一般 には，鎖を引つ張る場合において最も弱い輪が破壊するこ とにより鎖全体が破壊したとするモデル（最弱リンクモデ ル）として理解されている。最弱リンクモデルの応力を時 間に置き換えれば, 部品において寿命が最も短い部分が故 障することによって部品全体が故障したとするモデルとな る。1960 年代以降, 部品の劣化現象や寿命をワイブル分布 として扱うと, 測定データと良い一致が見られることから 広く利用されている。部品の劣化現象や寿命については, 正規分布，ポアソン分布では説明出来ないためである。

ワイブル分布が利用される背景は上記に述べたが，ここ では, ワイブル分布の式の利用， ワイブルプロットの活用 に焦点を当てて説明する。

ワイブルの不信頼度関数 $\mathrm{F}(\mathrm{t})$ は, 以下で与えられる。

$$
\mathrm{F}(\mathrm{t})=1-\exp \left\{\left(\left(\frac{t-\gamma}{\eta}\right)^{m}\right)\right\}
$$

ここで, $\mathrm{m}$ はワイブル係数 (形状パラメータ), $\eta$ は尺度パ ラメータ, $\gamma$ は位置パラメータである。

式 (5)で $\gamma=0$ とし，の両辺で 2 度対数を取ると,

$$
\log \log \left(\frac{1}{1-F(t)}\right)=m * \log (t)-m * \log (\eta)
$$

式(6) で

$\mathrm{X}=m * \log (t)$

$\mathrm{Y}=\log \log \left(\frac{1}{1-F(t)}\right)$

とし, $\eta$ は定数であるから $\mathrm{C}=-m^{*} \log (\eta)$ とすれば,

$\mathrm{Y}=\mathrm{mX}+\mathrm{C}$

実際のワイブルプロットは, 図 1 に示すように $\mathrm{Y}$ 軸に累積 不良率が表示され，Y 軸の第 2 軸に $\log \log (1 /(1-\mathrm{F}(\mathrm{t})))$ が目 盛ってあることに注意すべきである。累積不良率と $\log (\mathrm{t})$ は比例関係ではなく, $\log \log (1 /(1-\mathrm{F}(\mathrm{t})))$ と $\log (\mathrm{t})$ が比例関 係にあり，プロットしやすいように $\log \log (1 /(1-\mathrm{F}(\mathrm{t})))$ に対 応する $\mathrm{F}(\mathrm{t})$ がプロットしてある。

図 1 は実際に筆者が所属している ECM 研究会で得られ た試験結果で, 良く直線に乗っている。しかしながら, 図 1 の矢印の值が他と比較して非常に故障時間が早い。

そこで，データおよび故障状態を確認してはずれ值と判 断して, このデータを取り除いて, 再度, ワイブルプロッ トしたものが, 眓 2 である。

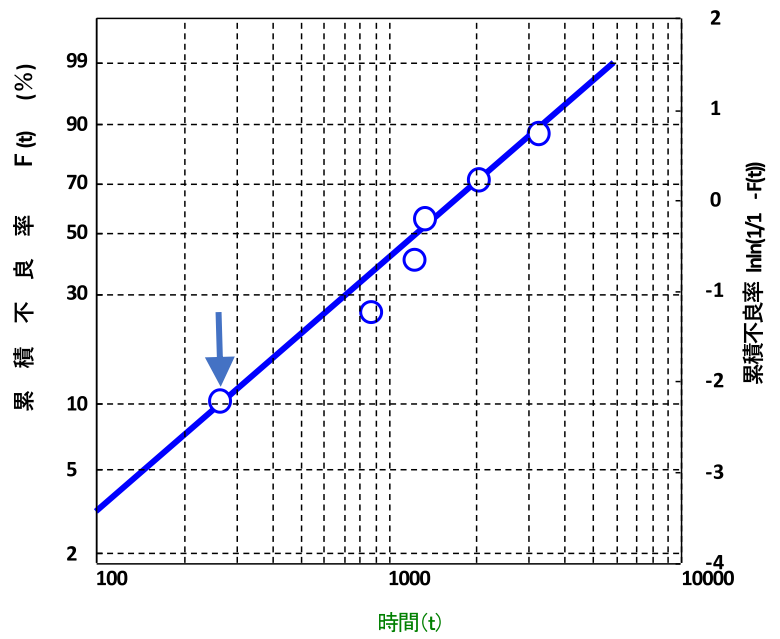

図 1. ワイブルプロット例

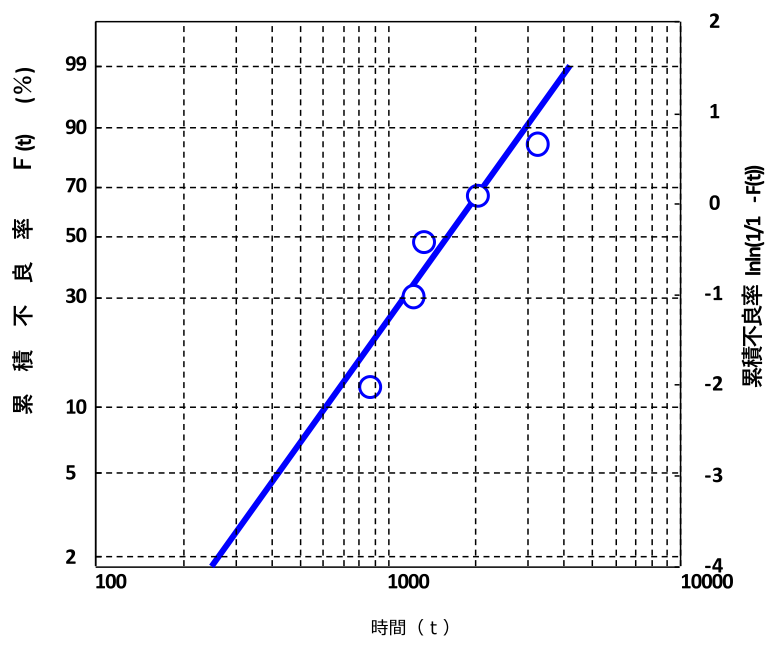

図 2. ワイブルプロット例（図 1 のはずれ値を除く）

図 1 のワイブル係数 $\mathrm{m}, \mathrm{MTBF}$ (平均故障時間), $\mathrm{B}_{10}$ の 值は, $1.08,2,544 \mathrm{~h}, 324 \mathrm{~h} て ゙$, 図 2 の場合には, それぞれ $1.22,1,688 \mathrm{~h}, 265 \mathrm{~h}$ となり, 重要な MTBF と $\mathrm{B}_{10}$ の值に大 きな違いが出ている。この例のように, 試験結果からワイ ブルプロット描画プログラムにただ単にデータを入力する だけでなく, 得られた結果に対する考察をしないと, 得ら れた結果が大きく違ってしまう。このような点にも留意す る必要がある。

寿命評価試験の結果は, 特殊な場合を除いてワイブル分 布に従うとの認識でほぼ問題ない。したがって，正規分布 を前提とした平均と標準偏差の関係が成立しないことに注 意する必要がある。

\subsection{1 外れ值の判断基準について}

3.3 節で説明したように，外れ值の取り扱いによって，ワ イブルプロットから得られるワイブル係数 $\mathrm{m}, \mathrm{MTBF}, \mathrm{B}_{10}$ などの值が違ってくるので，外れ值とするか否かの判断は 重要である。外れ值の判断基準について説明する。JIS B8672-1 で用いられている手法について説明する。まず異 常值かもしれない, 疑わしい寿命データを識別する必要が 
ある。このため, 大きさ $\mathrm{n}$ の標本による試験では, 得られ た寿命の標本平均 $\mathrm{x}$ 抒よび標本標準偏差 $\mathrm{s}$ を用いて, 次の 式から各データに対する $\mathrm{t}$ 值を計算する。 $\mathrm{t}$ の絶対值 $|\mathrm{t}|$ が 異常に大きいデー夕は，疑わしいデータである。

$$
\mathrm{t}=\frac{x_{i}-x}{s}
$$

ここで, $x_{i}$ : 個別の標本の寿命, $x$ : 寿命の標本平均,

$s$ : 寿命の標本標準偏差である。これは, 平均値から標準偏 差の何倍離れているかを計算しており, 標準偏差の 2 倍以 上離れたら疑わしいとの考え方である。

異常值か否かの判断は, JIS B8672-1 では, 外れ值が生じ る確率を求め, 例えば $5 \%$ 以下であれば異常值と判定して いるが, $\mathrm{t}$ 分布の知識などが必要なためここでは説明を省略 するが，JIS B8672-1を参照されたい。

ここでは, 疑わしいと判断したら, 試料の外観, 試験 データを確認して, 他の試料と比較して総合的な判断をし て，異常值と判断した根拠を記録することが重要だと指摘 しておく。

\subsection{2 累積故障率の計算について}

試験を実行すれば，故障時間が得られワイブルを扱うソ フトウェアに入力すれば, 結果が得られるが, 前節で説明 したように累積故障率を求めなければ，ワイブルプロット は得られない。ソフトウェアの中で, この累積故障率をど のような処理をしているかは重要である。

累積故障率 $\mathrm{F}\left(\mathrm{t}_{\mathrm{i}}\right)$ は,

$$
\mathrm{F}\left(\mathrm{t}_{\mathrm{i}}\right)=100 * \frac{N_{i}}{N}
$$

ここで, $N_{i}: \mathrm{i}$ 番目までの累積故障数 $\left(\Sigma n_{\mathrm{i}}\right)$

$$
\begin{aligned}
& \mathrm{n}_{\mathrm{i}}: \mathrm{i} \text { 番目の故障数 } \\
& N \text {; サンプル数 }
\end{aligned}
$$

である。

信頼性試験に使用するサンプル数は 30 以下であることが 多い。そのため, 順序統計量のばらつきが多いので，それ を補正するため,

a) 平均ランク法 $\mathrm{F}\left(\mathrm{t}_{\mathrm{i}}\right)=100 * \frac{N_{i}}{(N+1)}$

$$
\text { b) メディアンランク法 } \mathrm{F}\left(\mathrm{t}_{\mathrm{i}}\right)=100 * \frac{\left(N_{i}-0.3\right)}{(N+0.4)}
$$

のどちらかを使用している。サンプル数が少ないと結果が 違う可能性があるので，この点についても意識する必要が ある。

\subsection{MTBFについて}

MTBF（平均故障間隔）はシステムの信頼性を量る基本 的な尺度で, MTBF の数值が大きいほど信頼性が高いのは 間違いないが, MTBF は信頼性の目安であり, 耐用期間や 寿命を表すものではないことを認識する必要がある。

$3.5 B_{10}$ につて

$\mathrm{B}_{10}$ ライフは全体の $10 \%$ が故障する時間（動作回数など）
を言い，不信頼度 $\mathrm{F}(\mathrm{t})=0.1(\mathrm{R}(\mathrm{t})=0.9)$ における時間 $\mathrm{t}$ のこ とである。 $\mathrm{B}_{10}$ は図 3(a) にあるように，試験に投入したサ ンプル全体の $10 \%$ が故障した時間である。

$\mathrm{B}_{10}$ ライフが重視されるのは，メンテナンス（交換）時 期の目安となるもので, この意味合いから摩耗系故障を有 する機器に適用されることが多い。 $\mathrm{B}_{10}$ ライフで評価する 最も大きな理由は，信頼性のばらつきを考慮して評価する ことにある。図3(b) に示すように平均值 (MTTF) はほほ同 時間位置にあるが，分布のばらつき具合が異なる二つの分 布 $\mathrm{f}_{\mathrm{A}}(\mathrm{t}), \mathrm{f}_{\mathrm{B}}(\mathrm{t})$ を想定する。

MTTF の評価では MTTFA $\doteqdot$ MTTFB なので信頼性は同等 との評価になるが，最初の故障発生時間は $\mathrm{f}_{\mathrm{A}}(\mathrm{t})$ の方が明ら かに早く $\mathrm{B}_{10}$ ライフでの評価では $\mathrm{B}_{10 \mathrm{~A}}<\mathrm{B}_{10 \mathrm{~B}}$ となり, $\mathrm{f}_{\mathrm{B}}(\mathrm{t})$ の方が良い（寿命が長い）との結論となる。

\section{6 加速試験と加速係数 ${ }^{4)}$}

アレニウスの式についての説明は本特集号の別の記事で 説明されるので，ここではアレニウスモデルによる寿命と 温度の関係を使用して, 加速試験と加速係数について説明 する。

アレニウスによる寿命 $\mathrm{L}$ は，次のように定義されている。

$$
\begin{aligned}
& \mathrm{L}=\mathrm{A} * \exp \left(\frac{-E_{\mathrm{a}}}{R T}\right) \\
& \text { ここで, } \mathrm{A}: \text { 定数 } \\
& \mathrm{E}_{\mathrm{a}} \text { : 活性化エネルギ } \\
& \mathrm{R}: \text { ボルツマン定数 } \\
& \mathrm{T} ; \text { 絶対温度 }
\end{aligned}
$$

である。

実験によって，活性化エネルギが求まったとすると，式(9) によりある温度の寿命が求まる。2つの温度 $\mathrm{T}_{\mathrm{a}}$ (基準温度)

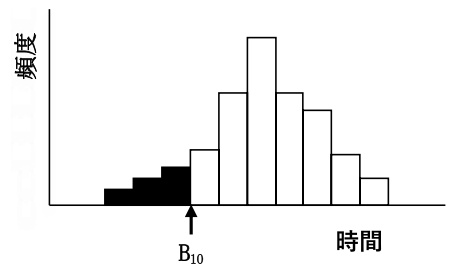

図 3(a). $B_{10}$ の説明図

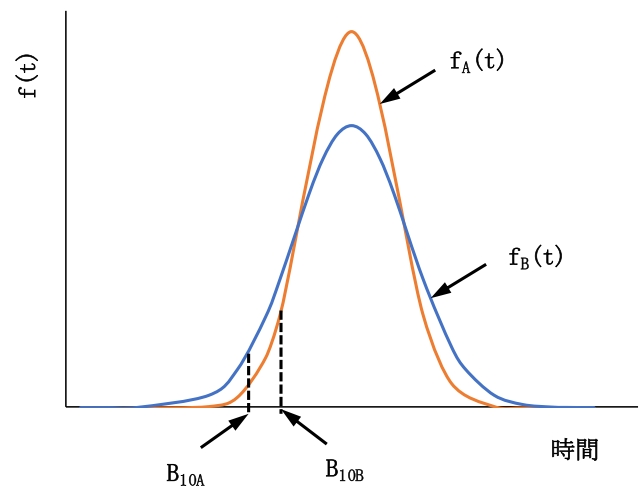

図 3(b). $B_{10}$ の違い 
表 2. HAST と THB 試験の比較

\begin{tabular}{c|c|c|c|c|c|c}
\hline \multicolumn{2}{c|}{$\mathrm{Ea}(\mathrm{eV})$} & 0.6 & 0.8 & 1.0 & 1.2 & 1.5 \\
\hline \multirow{3}{*}{ HAST } & $110^{\circ} \mathrm{C}$ & 3.56 & 5.43 & 8.29 & 12.7 & 23.9 \\
\cline { 2 - 7 } & $120^{\circ} \mathrm{C}$ & 5.65 & 10.1 & 17.9 & 31.9 & 75.8 \\
\cline { 2 - 7 } & $130^{\circ} \mathrm{C}$ & 8.77 & 18.1 & 37.3 & 76.8 & 228 \\
\hline
\end{tabular}

と $\mathrm{T}_{\mathrm{b}}$ (比較温度) との寿命の比 $\mathrm{AK}$ は, 式 (9) から

$$
\mathrm{AK}=\frac{L_{b}}{L_{\mathrm{a}}}=\left\{\frac{E_{\mathrm{a}}}{k}\left(\frac{1}{T_{\mathrm{a}}}-\frac{1}{T_{b}}\right)\right\}
$$

ここで, $\mathrm{T}_{\mathrm{a}}$ : 基準温度 $\left({ }^{\circ} \mathrm{k}\right)$

$\mathrm{T}_{\mathrm{b}}$ : 比較温度 $\left({ }^{\circ} \mathrm{k}\right)$

となる。

ここで，例として THB 試験 $\left(85^{\circ} \mathrm{C}, 85 \% \mathrm{RH}\right)$ と HAST と の加速係数を求めるため, (10) 式に Ea, 温度を代入して計 算すると，表 2 の結果が得られる。

表 2 は, HAST が例えば Ea $=0.6 \mathrm{eV}$, HAST 試験の温度 が $110^{\circ} \mathrm{C}$ の場合, THB 試験に対して 3.56 倍の加速となるこ とを意味している。そのため, 世の中では HAST 試験が使 用されることが多いが, HAST は $100^{\circ} \mathrm{C}$ 以上の高温での試 験なので，過酷試験となっていないかの判断が重要となる。

\section{4. 加速試験を有意義なものにするには}

時間とコストをかけて加速試験を有意義なものにするた めに必要な試験水準設定の考え方, 試験の打ち切り基準に ついて説明する。

\section{1 試験水準設定の考え方}

他の特集記号で説明される活性化エネルギを求めるため には, 少なくとも 3 水準の加速試験条件が必要となる。

実使用条件に近い条件 (最も弱い水準), 加速の大きい条 件（最強条件）の選び方で, 試験水準の間隔が多きいほど 寿命予測のばらつきが小さくなるとの報告がある ${ }^{5)}$

\section{2 試験の打ち切り基準について}

寿命試験においては，試験に投入した試料が故障するま で実施した方が, 寿命予測の精度が上がるのは間違いが無 いが，全て故障するまでとなると試験時間が長大となり， コストが膨大になってしまう。

どこまで試験を実施すれば，寿命を適切に評価できるか という指針の一つが存在する。これは, JIS B8672-1に $\mathrm{B}_{10}$ 寿命を適切に評価するために要求される最小故障数を示す 表が掲載されており，参考になる。その表を表 3 に示す。 また, $\mathrm{B}_{10}$ を求めるのに必要な最小の標本数は 7 である
表 3. $\mathrm{B}_{10}$ を求めるのに要求される必要故障数

\begin{tabular}{l|l|l|l|r|c}
\hline 標本の大きさ & 7 & 8 & 9 & 10 & 11 以上 \\
\hline 要求最小故障数 & 5 & 6 & 7 & 7 & 標本の大きさの $70 \%$, 端数切捨て注 \\
\hline
\end{tabular}

注）例えば，標本の大きさが 11 の場合，要求最小故障数は 7 である。

と JIS B8672-1 に記載されている。その理由は, (8) 式で $N=$ 7, $N_{i}=1$ とし計算すると, $\mathrm{F}\left(\mathrm{t}_{1}\right)=9.5 \%$ となり, 故障確率 $10 \%$ の寿命 $\mathrm{B}_{10}$ より少し小さい故障時間が試験で得られる からである。

ともあれ，標本の大きさの $70 \%$ 以上が故障するまで試験 するとの考えは参考になる。

\section{5. まとめ}

加速試験について説明すべき項目は非常に多いが，加速 試験に必要なサンプル数の根拠，ワイブル分布，加速試験 の考え方について解説した。解説で留意したことは，出来 るだけ根拠となる理論，説明を重視すると共に，広く認知 されているJIS を参考にすることに努めた。

十分とは言えないと思うが, 参考になることも多いと思 うので，今後の信頼性の業務に役立つことを願うものであ る。

(2018.4.30- 受理)

\section{文献}

1) 真壁 肇編：“信頼性工学入門,” 日本規格協会, 1996

2) W. Weibull: “A Statistical Distribution Function of Wide Applicability," Journal of Applied Mechanics, 1951

3）日科技連編：“信頼性データの解析一日科技連ワイブル確率 紙の使い方,”日科技連ライブラリー12, 1967

4) 山本敏男：“加速試験と信頼性へのガイダンス,” ESPEC 技 術情報，No. 4

5) 清水貴宏：“加速寿命試験に必要な試験水準の設定と故障 デー夕に関する考察,”日科技研，2011

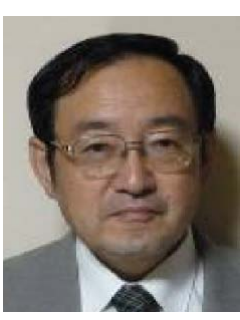

岡本秀孝（おかもと ひでたか）

著者紹介 1977 年 電気通信大学 修士課程修了。同年 日 本電信電話公社入社。現在，一般財団法人日本 規格協会勤務。JIEP 会員, TC104 エキスパート 